\title{
Insulin Receptors in the Fetal Rat Lung. A Transient Characteristic of Fetal Cells?
}

\author{
FRANÇOISE R. SODOYEZ-GOFFAUX, ${ }^{(20)}$ JEAN C. SODOYEZ, AND CLAUDINE J. DE VOS
}

Departments of Pediatrics and Internal Medicine, University of Liege, Liege, B-4020, Belgium

\begin{abstract}
Summary
${ }^{125}$ I-Tyr insulin ( ${ }^{125}$ I-Tyr Ins) was injected into the vitelline vein of rat fetuses in utero after 17, 19, or 21 days of gestation. Three min later, the weight and radioactivity of various organs and of the remaining carcass were measured. A radioactivity concentration index (RCI) was calculated by dividing the specific activity of each organ by that of the whole feto-placental unit. In each of the three age groups studied, the RCI indicated that ${ }^{125}$ I-Tyr Ins was concentrated in several organs, notably the liver and kidneys. The lungs also concentrated the labeled hormone; however, only the youngest fetuses revaled significantly elevated levels. Lung RCIs were $1.68 \pm 0.27,0.67 \pm 0.12$, and $0.85 \pm 0.18$ after 17,19 , and 21 days of gestation, respectively. Three, 9 and 15 min after ${ }^{125}$-I-Tyr Ins injection, the lungs and liver of 17-day postcoitum fetuses were homogenized and then subjected to gel chromatography. During the $15 \mathrm{~min}$ period of investigation, the percentage of intact labeled hormone in the liver and lungs decreased while the percentage of ${ }^{125}$ I-tyrosine increased.

Autoradiographs of the fetal lungs indicated that the pseudoglandular cells bound ${ }^{125} \mathrm{I}$-Tyr Ins (surface density of grains 9 min after ${ }^{125}$ I-Tyr Ins alone, $1.71 \pm 0.22$ ) and that this process was inhibited by coinjection of $100 \mathrm{mU}$ unlabeled insulin (surface density of grains, $0.50 \pm 0.16 ; P<0.001$ ). At $9 \mathrm{~min}$, the surface density of grains on the bronchial tubes was only six times less than that of the hepatocytes of the same fetuses. It was concluded that epithelial lung cells during the pseudoglandular stage are equipped with numerous insulin receptors and appear capable of degrading insulin. The concentration of receptors markedly decreased at a later stage of lung development.
\end{abstract}

\section{Speculation}

It is speculated that insulin receptors may modulate lung glycogen metabolism. Their presence would favor accumulation of glycogen during the pseudoglandular stage whereas their partial disappearance at a later stage of maturation would allow glycogen breakdown and surfactant synthesis.

An increasing number of reports suggest that insulin may affect lung metabolism. Glucose oxidation (7), 2-deoxy-D-glucose uptake (2), incorporation of ${ }^{3} \mathrm{H}$ leucine into proteins (7), and incorporation of glucose into phospholipids (8) are decreased in lungs of diabetic rats but return to normal values after insulin treatment (7). However, insulin was found to have no direct effect when added to the incubation medium of adult lung slices (7). It would, of course, be a dangerous oversimplification to equate diabetes with a mere lack of insulin. A crude membrane preparation isolated from rat lungs exhibited an insulin binding capacity which fulfilled the classical criteria for true insulin receptors (7). However, this membrane preparation represented a heterogeneous cell population, and, as noted by these authors, evidence was lacking that those cells which carried the insulin binding sites were the ones where glucose metabolism was somehow affected by diabetes
(7). In adult human pathology, disorders of lung elasticity have been associated with juvenile onset diabetes (12), but this observation was not confirmed one year later (11). To our knowledge, no lung disorder has been attributed to hyperinsulinemia.

Infants of diabetic mothers are known to have a high incidence of respiratory distress syndrome (10). In these infants, surfactant deficiency has been tentatively linked to concomitant hyperinsulinemia. Insulin has been found to inhibit cortisol-induced lecithin synthesis in cultured fetal rabbit pneumocytes (14) and the production of phosphatidylcholine and lysophosphatidylcholine by fetal rabbit lung slices (9). Thus, it appears that perinatal lung cells may be more sensitive to insulin than adult pneumocytes.

This prompted us to investigate the presence of insulin receptors during various stages of lung development, including the pseudoglandular stage. The pseudoglandular lung cells are characterized by large glycogen stores. During cytodifferentiation, glycogen stores are broken down and surfactant synthesis is initiated. As previously suggested, these two events might be linked, glycogen providing the precursors of phospholipid synthesis (3).

\section{MATERIALS AND METHODS}

\section{ANIMALS}

Female albino rats weighing 230 to $260 \mathrm{~g}$ were caged overnight with a male so that the duration of pregnancy could be determined with a $12 \mathrm{hr}$ error. Seventeen, 19, or 21 days postcoitum (pc), the pregnant rats were anesthetized with nembutal (intraperitoneal, $15 \mathrm{mg}$ ), and the uterus was visualized through a median abdominal incision. Starting at the distal portion of each horn, the smallest possible portion of the uterus was exteriorized and cut on the side opposite to that of placental insertion. Labeled insulin (circa 0.1 $\mu \mathrm{Ci}$ ), alone or mixed with an excess of unlabeled hormone, was injected into the vitelline vein of the intact fetuses in utero, using a $10 \mu 1$ Hamilton microsyringe equipped with a $26 \mathrm{~S}$ gauge needle. Care was taken not to perforate the fetal membranes. At selected times, the fetuses were removed and analyzed for the distribution of organ radioactivity.

\section{LABELED AND UNLABELED INSULIN}

Highly purified bovine insulin was monoiodinated and purified by a previously described method (15). Specific activity was 200 to $300 \mu \mathrm{Ci} / \mu \mathrm{g}$. After an overnight incubation at $4^{\circ} \mathrm{C}$, immunoprecipitability was over $85 \%$. Before use, the labeled hormone was rechromatographed on G50 Sephadex to remove contaminating substances of high and low molecular weight. The unlabeled hormone was pork monocomponent insulin kindly provided by the Novo Company, Copenhagen, Denmark.

\section{AUTORADIOGRAPHIC STUDIES}

Seventeen-day $\mathrm{pc}$ fetuses were given injections intravenously with 0.75 to $1.35 \mu \mathrm{Ci}{ }^{125} \mathrm{I}$-Tyr insulin (in $10 \mu \mathrm{l}$ ) alone or mixed with $100 \mathrm{mU}$ unlabeled insulin. The fetuses were sacrificed 3 or 
9 min later. Their lungs were rapidly removed, fixed in $4 \%$ glutaraldehyde in 0.15 mole/liter phosphate buffer ( $\mathrm{pH} 7.4$ ), postfixed in $1 \%$ osmium tetroxide, embedded in epon, and cut into 1$\mu$ thick sections using a Sorvall-Porter-Blum MT1 ultramicrotome. The sections were coated with Ilford L4 emulsion and allowed to stand $7 \mathrm{wk}$ at $4^{\circ} \mathrm{C}$. Emulsions were revealed in $4 \%$ Rodinal and fixed in $250 \mathrm{~g} /$ liter sodium thiosulfate. The sections were colored with $1 \%$ toluidine blue $(\mathrm{pH} 9)$. For each lung preparation, six photomicrographs were taken under immersion $(\times 330$ on the 24 $\times 36 \mathrm{~mm}$ negative), and on each photomicrograph, all the silver grains (100 to 150) were counted. The surface of epithelial cells and of mesenchymal tissue was measured using a Leitz-Image Analysis System. The livers of the same fetuses were similarly studied.

\section{ANALYSIS OF LUNG RADIOACTIVITY}

Seventeen day pc fetuses received an IV injection of $0.75 \mu \mathrm{Ci}$ ${ }^{125}$ I-Tyr Ins. Three, 9, or 15 min later, the lungs were removed.

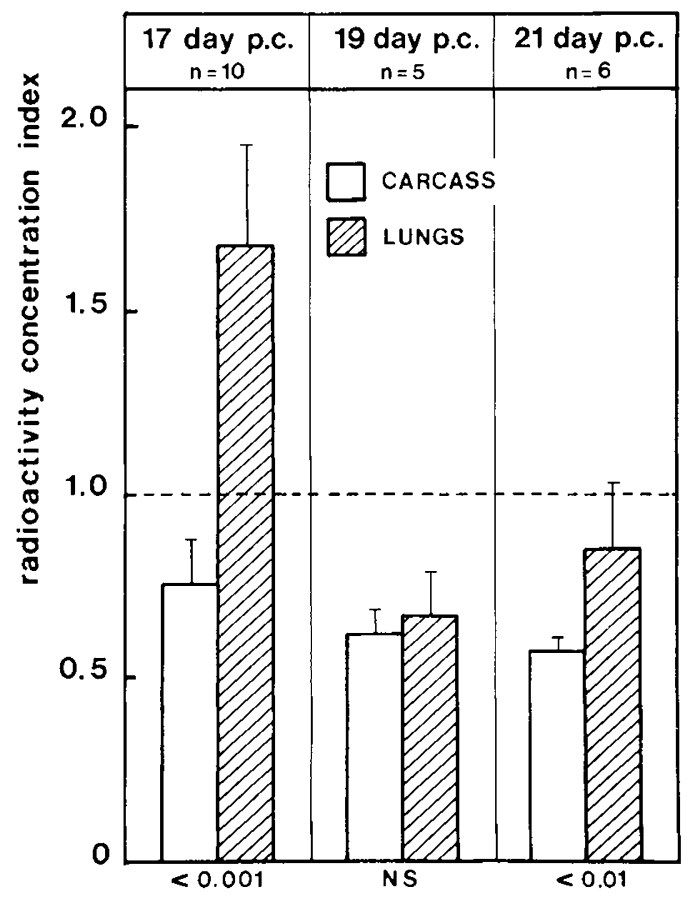

Fig. 1. Radioactivity concentration index of lungs and carcass of 17 19-, and 21 -day pc fetuses $3 \mathrm{~min}$ after IV injection of ${ }^{125} \mathrm{I}$-Tyr Ins. Average \pm S.D.
They were rapidly homogenized in $3 \mathrm{ml}$ ice-cold 1 mole/liter acetic acid using a Polytron PT10. The homogenate was centrifuged at $2500 \times g$ for $30 \mathrm{~min}$. Over $90 \%$ of the radioactivity was recovered in the supernatant. The supernatant was lyophilized and stored at $-25^{\circ} \mathrm{C}$ until chromatographed. The dry residue was redissolved in $1 \mathrm{ml} 7$ moles/liter urea, 1 mole/liter acetic acid and chromatographed on a $61 \times 1.2 \mathrm{~cm}$ G50 F Sephadex column eluted with the same solvent at a flow rate of $3 \mathrm{ml} / \mathrm{hr}$. One $\mathrm{ml}$ fractions were collected and analyzed for radioactivity.

The lungs of a control fetus were transferred into $3 \mathrm{ml} \mathrm{l} \mathrm{mole/}$ liter acetic acid to which ${ }^{125}$ I-Tyr Ins $(35,000 \mathrm{cpm})$ had previously been added. This sample was homogenized and further processed in the same manner as had the lungs of the injected fetuses. It was used as a control for ${ }^{125}$ I-Tyr Ins degradation during the homogenization, storage, and chromatographic procedure.

The Sephadex column was calibrated with Dextran Blue T 2000 (exterior volume, Vo), ${ }^{125} \mathrm{I}$-Tyr Ins $\left(\mathrm{V}_{125_{1} \text {-Tyr Inn }}\right)$ and ${ }^{127} \mathrm{I}$-tyrosine $\left(\mathrm{V}_{12 \mathrm{i}_{\mathrm{I}} \mathrm{T} \mathrm{Tr}}\right)$.

Liver radioactivity was similarly analyzed except that homogenization was performed in $10 \mathrm{ml}$ of 7 moles/liter urea 1 mole/liter acetic acid and the supernatants were stored frozen.

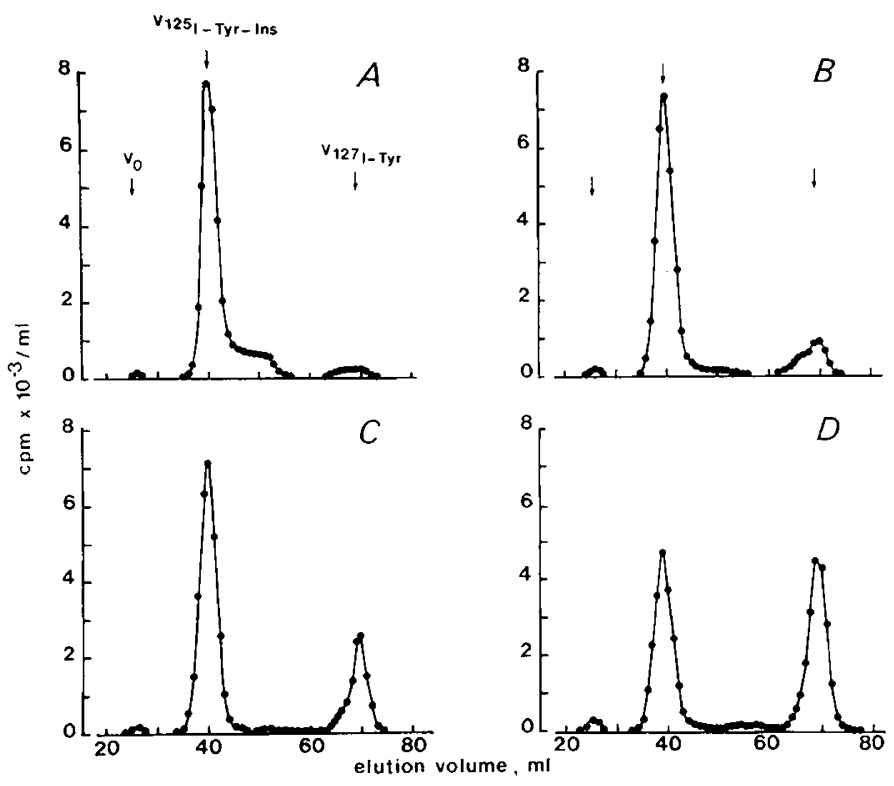

Fig. 2. Elution profiles of lung extracts after G-50 Sephadex chromatography. ${ }^{12: 5} \mathrm{I}$-Tyr Ins was added before lung homogenization $(A)$ or injected IV 3, 6, or $9 \mathrm{~min}$ before lung removal and homogenization ( $B$ to D).

Table 1. Analysis of lung and liver radioactivity following an IV bolus injection of ${ }^{125} \mathrm{I}-\mathrm{Tyr}$ Ins into 17 -day pc rat fetuses

\begin{tabular}{|c|c|c|c|c|c|c|}
\hline & & Lung & & & Liver & \\
\hline $\begin{array}{l}\text { Time after IV injection of }{ }^{12.5} \mathrm{I}-\mathrm{Tyr} \\
\text { Ins (min) }\end{array}$ & 3 & 9 & 15 & 3 & 9 & 15 \\
\hline \multicolumn{7}{|l|}{$\begin{array}{l}\% \text { of organ radioactivity identified } \\
\text { as }\end{array}$} \\
\hline \multicolumn{7}{|l|}{ Concentration of } \\
\hline${ }^{125} \mathrm{I}-\mathrm{Tyr}$ Ins (cpm/mg) & 106 & 98 & 70 & 276 & 200 & 118 \\
\hline${ }^{125} \mathrm{I}-\mathrm{Tyr}(\mathrm{cpm} / \mathrm{mg})$ & 21 & 36 & 69 & 19 & 101 & 133 \\
\hline
\end{tabular}

\footnotetext{
${ }^{1}$ The results were normalized for $100,000 \mathrm{cpm}$ recovered in the fetoplacental unit.
} 


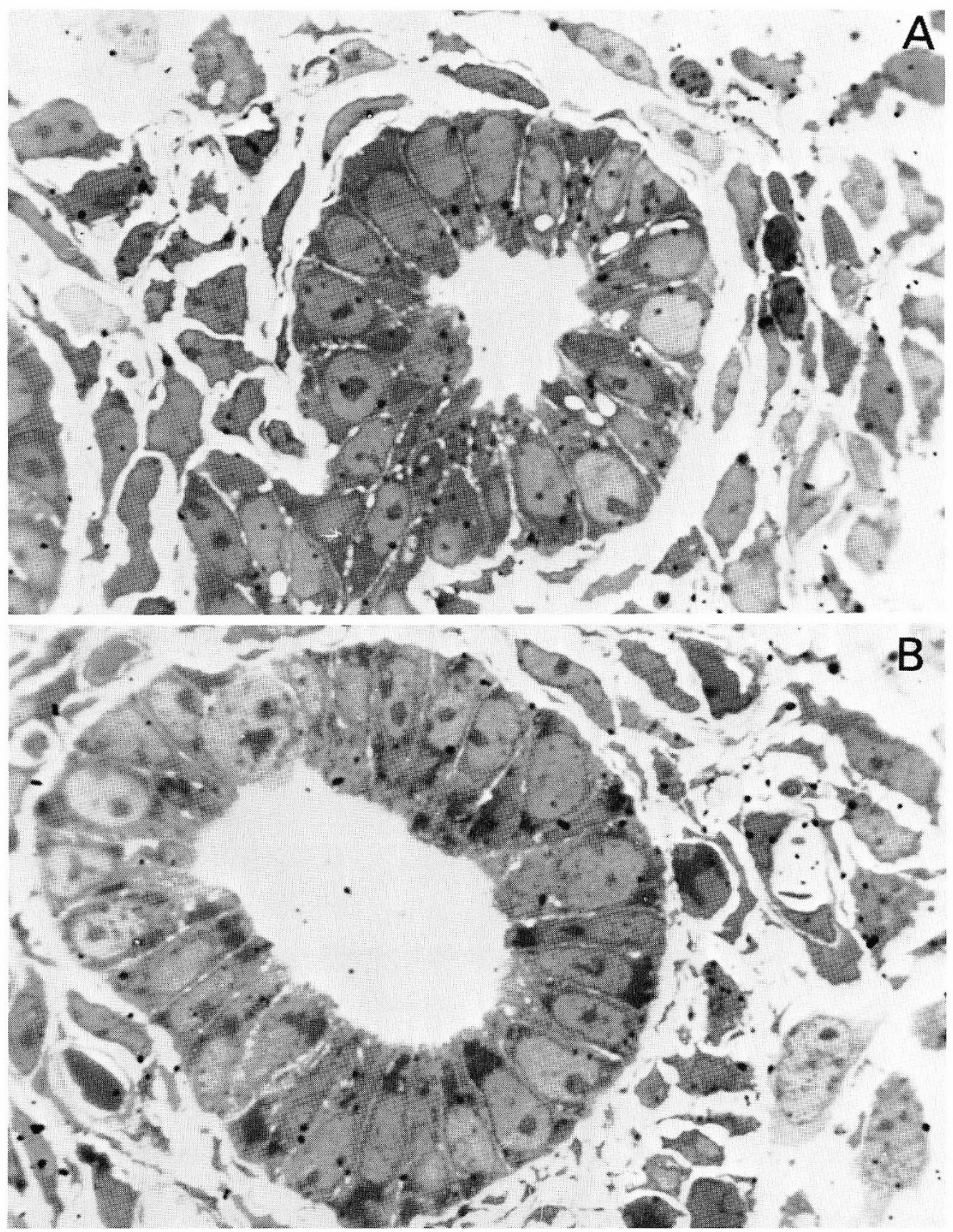

Fig. 3. Autoradiograph of fetal lungs 9 min after IV injection of ${ }^{125} \mathrm{I}$-Tyr Ins alone $(A)$ or mixed with an excess of unlabeled insulin $(B)$. $\times 330$ on the $24 \times 36$ negative.

\section{RESULTS}

The search for organs rich in insulin receptors was performed by measuring the specific activity of various fetal organs $3 \mathrm{~min}$ after IV injection of ${ }^{125}$ I-Tyr Ins. This value, divided by the specific activity of the whole feto-placental unit, yielded a "radioactivity concentration index" (RCI) for each organ. A RCI that is less than one is considered to be an indication that the organ has little or no insulin concentrating activity, whereas a RCI greater than one suggests that the organ accumulates insulin. Based on this approach, several fetal organs, notably the liver and kidneys, appeared to concentrate insulin throughout the studied period of gestation. Insulin binding in the liver was inhibited by coinjection of $100 \mathrm{mU}$ unlabeled insulin (saturable binding), whereas insulin uptake by the kidneys was not (unsaturable uptake) $(16,17,18)$. The lungs appeared to concentrate significantly the labeled hor- mone in only the youngest fetuses. This is illustrated in Fig. 1 in which the lung RCIs of 17-, 19-, and 21-day pc fetuses were compared to those of the corresponding carcasses. In this experiment, carcass was defined as whole fetoplacental unit after removal of the placenta, liver, heart, kidneys, and lungs.

Three min after injection, the amount of recorded radioactivity in the lungs represented $3.76 \%$ of the total injected. Lung radioactivity varied little during the following $12 \mathrm{~min}$ (Table 1). The lungs of a 17-day pc fetus were homogenized in the presence of ${ }^{125}$ I-Tyr Ins, and the extract was chromatographed. As shown by Fig. $2 A$, the labeled hormone, which was added, remained undamaged throughout the experimental procedure of homogenization, storage, and chromatography. The fetal lungs, removed 3, 9, and 15 min after ${ }^{125}$ I-Tyr Ins injection, were analyzed using the same technique. The elution profiles of lung radioactivity are illustrated 
in Fig. $2(B$ to $D)$, and the respective percentages of ${ }^{125} \mathrm{I}$-Tyr Ins and ${ }^{725}$ I-Tyr were calculated (Table 1). Knowing the total lung radioactivity, the relative proportions of ${ }^{125} \mathrm{I}$-Tyr Ins, and of ${ }^{125} \mathrm{I}$ Tyr, and the organ weight, we calculated the lung concentration of both radioactive substances (Table 1).

For the sake of comparison, liver radioactivity was similarly analyzed (Table 1). At $3 \mathrm{~min}$, the ${ }^{125} \mathrm{I}$-Tyr Ins concentration was 3 times higher in the liver than in the lungs, whereas the concentration of ${ }^{125} \mathrm{I}-\mathrm{Ty}$ was the same in both the liver and lungs. With time, ${ }^{125}$ I-Tyr Ins concentration decreased and ${ }^{125} I$-Tyr concentration increased in the liver, indicating that this organ actively degraded the labeled hormone. A similar process occurred in the lungs albeit at a slower rate.

Autoradiographs of semi-thin sections of lungs taken $9 \mathrm{~min}$ after injection of ${ }^{125}$ I-Tyr Ins alone or mixed with an excess of unlabeled insulin are illustrated in Fig. 3. In these figures, the lungs are at the pseudoglandular stage. The bronchial tubes are characterized as highly columnar, glycogen laden, and singularly layered epithelial cells. They are surrounded by mesenchyme which is rich in capillaries. The surface density of silver grains was measured on the bronchial tubes, on their lumen, and on the mesenchyme (Table 2).

In all four conditions examined, the surface density of silver grains did not significantly vary in the bronchial tube lumina or in the connective tissue. By contrast, the surface density of reduced silver grains on the epithelial cells was significantly reduced when an excess of unlabeled insulin was coinjected with the iodinated hormone. The livers of the very same rats were similarly analyzed, and the surface density of grains on the hepatocytes was measured (Table 2). Contrary to the pseudoglandular cells in which insulin binding reached a maximum between 3 and $9 \mathrm{~min}$, binding to the hepatocytes reached a maximum $3 \mathrm{~min}$ after injection. It is noteworthy that the surface density of grains of the liver was nine and six times higher than that of the corresponding lungs at 3 and 9 min, respectively.

\section{DISCUSSION}

The organ distribution of ${ }^{125} \mathrm{I}$-Tyr Ins after vitelline vein injection obviously depends upon a number of factors other than the concentration of insulin receptors. For example, kidneys concentrate the filtered insulin in the proximal tubules, and this process is largely related to glomerular filtration rate and tubular cells integrity. For organs rich in insulin receptors, binding of injected ${ }^{125}$ I-Tyr Ins depends upon blood flow and rapidity of exchanges between blood and target cells. In this regard, the respective situations of the liver and lungs are quite different. Firstly, fetal pulmonary circulation is a physiologically low volume system due to atrial and ductal shunting. Secondly, hepatocytes are in close contact with circulating blood, whereas in 17-day pc fetuses, the mesenchyme is interposed between the lung capillaries and bronchial tubes. These two structures will come into closer contact at the canalicular stage. It may therefore be expected that maximum binding of ${ }^{125} \mathrm{I}$-Tyr Ins will occur sooner in the liver than in the lung pseudoglandular cells. Increasing insulin binding to the bronchial tubes between 3 and 9 min had little effect on total lung radioactivity probably because bronchial tubes are but a fraction of total lung tissue. In spite of the low lung perfusion, it is noteworthy to point out that the surface density of grains on the epithelial lung cells was less than one order of magnitude below that of the hepatocytes of the same fetuses.

Labeled degradation products, ${ }^{125} \mathrm{I}-\mathrm{Ty}$, progressively appeared in both lungs and livers, suggesting that both organs degraded the bound hormone. There is a possibility that degradation products found in the lungs could originate from the liver; however, this is unlikely. Indeed, the fetal liver slowly expelled ${ }^{125} \mathrm{I}-\mathrm{Ty}$, as evidenced by the sluggish decrease of total liver radioactivity over the period studied. In addition, in more mature fetuses, we have previously reported that the plasma concentration of ${ }^{125}$ I-Tyr Ins degradation products increased very slowly with time (17).

It may be estimated that injected ${ }^{125} \mathrm{I}$-Tyr Ins reached a plasma concentration on the order of $1 \times 10^{-10}$ moles/liter in experiments designed to measure lung radioactivity concentration index and 1 $\times 10^{-9}$ moles/liter for chromatographic and autoradiographic studies. Binding sites that bind their ligand at such low concentrations may be reasonably called high affinity binding sites.

Altogether, these data indicate that the pseudoglandular fetal lung cells are equipped with high affinity and saturable insulin receptors.

As the lungs evolved from the pseudoglandular to the canalicular ( 19 day pc) and alveolar stages (21 day pc) (6), the relative proportion of mesenchymal to epithelial cells decreased. Yet, this coincided with a decreased lung insulin binding capacity, suggesting that insulin receptors are a temporary property of fetal lung cells. It is tempting to speculate that these insulin receptors are useful at an early stage of the development when the lung cells grow and accumulate glycogen and that their partial disappearance at a later stage of maturation derepresses glycogen breakdown and surfactant synthesis. These results are in good agreement with the observation by Gross et al. (4) that insulin enhances glycogen synthesis by pseudoglandular cells in culture.

Blood cells have been shown to partially or totally lose their insulin receptors as they age and/or evolve from a fetal to an adult stage $(1,5,13,19)$. This phenomenon may be more general because, as we now report, it occurs during the ontogenesis of epithelial cells.

\section{REFERENCES AND NOTES}

1. Dons, R. F., Corash, L. M., and Gorden, P.: Human erythrocyte insulin binding decreases as an exponential function of cell age. Diabetes (Abstract), 29 (Suppl. 2): 98 (1980)

2. Fricke, R. F., and Longmore, W. J.: Effects of insulin and diabetes on 2-deoxyD-glucose uptake by the isolated perfused rat lung. J. Biol. Chem., 254: 5092 (1979).

Table 2. Surface density of reduced silver grains in the lungs and hepatocytes of 17-day pc fetuses 3 or 9 min after IV injection of $1 \mu C i$ ${ }^{125} \mathrm{I}$-Tyr Ins alone or mixed with $100 \mathrm{mU}$ unlabeled insulin

\begin{tabular}{|c|c|c|c|c|c|c|c|}
\hline \multirow[b]{2}{*}{$\begin{array}{l}\text { Time after } \\
\text { injection }\end{array}$} & \multirow{2}{*}{$\begin{array}{c}\text { Excess } \\
\text { unlabeled } \\
\text { insulin }\end{array}$} & \multicolumn{4}{|c|}{ Lungs $^{1}$} & \multicolumn{2}{|c|}{ Livers $^{1}$} \\
\hline & & $n^{2}$ & $\begin{array}{l}\text { Bronchial tube } \\
\text { cells }\end{array}$ & $\begin{array}{l}\text { Bronchial tube } \\
\text { lumen }\end{array}$ & $\begin{array}{c}\text { Mesenchyme and } \\
\text { capillaries }\end{array}$ & $n^{2}$ & Hepatocytes \\
\hline \multirow[t]{2}{*}{$3 \mathrm{~min}$} & 0 & 6 & $0.96 \pm 0.14^{3}$ & $0.33 \pm 0.19$ & $0.79 \pm 0.10$ & 5 & $8.58 \pm 0.57$ \\
\hline & + & 6 & $0.40 \pm 0.19^{4}$ & $0.30 \pm 0.37$ & $0.80 \pm 0.43$ & 6 & $2.72 \pm 0.35^{4}$ \\
\hline \multirow[t]{2}{*}{$9 \mathrm{~min}$} & 0 & 6 & $1.71 \pm 0.22^{5}$ & $0.18 \pm 0.23$ & $0.96 \pm 0.19$ & 5 & $10.01 \pm 1.83$ \\
\hline & + & 7 & $0.50 \pm 0.16^{4}$ & $0.43 \pm 0.40$ & $0.87 \pm 0.11$ & 6 & $3.74 \pm 0.56^{4}$ \\
\hline
\end{tabular}

\footnotetext{
'Grains $/ \mathrm{cm}^{2}$.

${ }^{2}$ Number of examined photographs.

${ }^{3}$ Mean \pm S.D

${ }^{4}$ Different from the organ dissected at the same time but after labeled hormone alone; $P<0.001$

"Different from the lung dissected $3 \mathrm{~min}$ after injection of the labeled hormone alone; $P<0.001$.
} 
3. Gilden, C., Sevanian, A., Tierney, D. F., Kaplan, S. A., and Barret, C. T.: Regulation of fetal lung phosphatidyl choline synthesis by cortisol: role of glycogen and glucose. Pediatr. Res., I1: 845 (1977).

4. Gross, I., Walker Smith, G. J., Maniscalco, W. M., Czajka, M. R., Wilson, C. M., and Rooney, S. A.: An organ culture model for study of biochemical development of fetal rat lung. J. Appl. Physiol. Respir. Environ. Exercise Physiol., 45: 355 (1978)

5. Herzberg, V. L., Boughter, J. M., Carlisle, S. K., Ahmad, F., and Hill, D. E.: ${ }^{125}$ IInsulin receptor binding to cord blood erythrocytes of varying gestational age and comparison with adult values. Pediatr. Res., 14: 4 (1980).

6. Meyrick, B., and Reid, L. M.: Ultrastructure of alveolar lining and its development. In: W. A. Hodson: Development of the Lung. pp. 135-214 (Marcel Dekker Inc., New York, 1977).

7. Morishige, W. K., Uetake, C. A., Greenwood, F. C., and Akaka, J.: Pulmonary insulin responsivity: in vivo effects of insulin on the diabetic rat lung and specific insulin binding to lung receptors in normal rats. Endocrinology, 100: 1710 (1977).

8. Moxley, M. A., and Longmore, W. J.: Effect of experimental diabetes and insulin on lipid metabolism in the isolated perfused rat lung. Biochim. Biophys. Acta, 488: $218(1977)$

9. Neufeld, N. D., Sevanian, A., Barret, C. T., and Kaplan, S. A.: Inhibition of surfactant production by insulin in fetal rabbit lung slices. Pediatr. Res., 13: 752 (1979).

10. Robert, M. F., Neff, R. K., Hubbell, J. P., Taeusch, H. W., and Avery, M. E.: Association between maternal diabetes and the respiratory-distress syndrome in the newborn. N. Engl. J. Med., 294: 357 (1976).

11. Schernthaner, G., Haber, P., Kummer, F., and Ludwig, H.: Lung elasticity in juvenile-onset diabetes mellitus. Am. Rev. Respir. Dis., 116: 544 (1977).

12. Schuyler, M. R., Niewoehner, D. E., Inkley, S. R., and Kohn. R.: Abnormal lung elasticity in juvenile diabetes mellitus. Am. Rev. Respir. Dis., 113: 37 (1976)

13. Sinha, M.. Velayo, N., Voina, S., and Ganguli, S.: The erythrocyte insulin receptor of sheep: presence in the fetus and absence in the adult. Diabetes (Abstract), 29 (Suppl. 2): 101 (1980).

14. Smith, B. T., Giroud, C. J. P., Robert, M., and Avery, M. E.: Insulin antagonism of cortisol action on lecithin synthesis by cultured fetal lung cells. J. Pediatr. 87: 953 (1975).

15. Sodoyez, J. C., Sodoyez-Goffaux, F., Goff, M. M., Zimmerman, A. E., and Arquilla, E. R.: [ $\left.{ }^{[27} \mathrm{I}\right]$-or carrier free $\left[{ }^{125} \mathrm{I}\right]$ monoiodoinsulin. Preparation, physical, immunological and biological properties and susceptibility to "insulinase" degradation. J. Biol. Chem., 250: 4268 (1975).

16. Sodoyez, J. C., Sodoyez-Goffaux, F. R., and Moris, Y. M.: ${ }^{125}$ I-Insulin: kinetics of interaction with its receptors and rate of degradation in vivo. Am. J. Physiol., 239: E3 (1980).

17. Sodoyez-Goffaux, F. R., Sodoyez, J. C., and De Vos, C. J.: Insulin secretion and metabolism during the perinatal period in the rat. Evidence for a placental role in fetal hyperinsulinemia. J. Clin. Invest., 63: 1095 (1979).

18. Sodoyez-Goffaux, F. R., Sodoyez, J. C., Thiry-Moris, Y. M., and De Vos, C.: Demonstration of insulin receptors in the rat fetus in vivo. Diabetes (Abstract), 29 (Suppl. 2): 97 (1980).

19. Thorsson, A. V., and Hintz, R. L.: Insulin receptors in the newborn. Increase in receptor affinity and number. N. Engl. J. Med., 297: 908 (1977).

20. Requests for reprints should be addressed to: Dr. F. Sodoyez-Goffaux, Dpt. Pediatrics, University of Liege, Hôpital de Bavière, 66 Bd de la Constitution, B-4020, Liege, Belgium.

21. This research was supported in part by grants of the National Fund for Scientific Research, Brussels, Belgium. The valuable collaboration and advice of Prof. $E$. H. Betz and L. Simar (Department of Pathology) are gratefully acknowledged. We are thankful to Dr. Williot for bibliographic assistance and to $\mathbf{M}$. Fodor for excellent secretarial assistance.

22. Received for publication September 16, 1980

23. Accepted for publication December 10, 1980 . 